\title{
Distribution and Diversity of Malus Germplasm Resources in Yunnan, China
}

\author{
Wenbin Zhang' and Junru Zhang \\ Horticultural Institute, Yunnan Academy of Agricultural Sciences, Longtouje, Kunming, Yunnan, \\ People's Republic of China \\ Xulan $\mathbf{H u}^{2}$ \\ Yunnan Agricultural Extension Center, 3 Xinwen South Road, Kunming, Yunnan, People's Republic of China
}

The Yunnan Province is situated in the southwestern region of China, between long. $97^{\circ} 39^{\prime} \mathrm{E}$ to $106^{\circ} 02^{\prime} \mathrm{E}$ and lat. $21^{\circ} 09^{\prime} \mathrm{N}$ to $29^{\circ} 15^{\prime} \mathrm{N}$. The province borders Burma to the west, Laos and Vietnam to the south, the provinces of Sichuan and Tibet to the north, and Guizhou and Guangxi to the east (Fig. 1). Yunnan is part of the Yun-Gui Plateau, with an average elevation of $2000 \mathrm{~m}$ above sea level. Its topography slopes from the northwest to the southeast, with a complex terrain and vast attitudinal differences.

A subtropical monsoon climate prevails in the province, with varied climatic conditions; however, tropical, subtropical, temperate, and frigid climates exist throughout the province. The Yunnan people say that four seasons can be found simultaneously along the same mountain slope, and different weather conditions can be experienced over a distance of $5 \mathrm{~km}$.

The province has a vast territory and is generously endowed with natural resources. It is renowned as "the kingdom of plants" in China because of the amazing diversity. There are 15,000 native species of higher plants in this area, which account for more than onehalf of China's total plant germplasm. More than 200 fruit tree species from 41 families originated from Yunnan ( $\mathrm{Hu}, 1988)$.

\section{Malus spp. indigenous to Yunnan and their distribution}

According to Chinese plant taxonomist D. $\mathrm{Yu}, 23$ Malus spp. are native to China (Yu, 1978, 1979). Anew species, Malusxiaojinensis (Cheng et Jiang), from Sichuan Province was reported (Cheng et al., 1983), bringing the total to 24 species. Wu (1984) reported that 13 Malus spp. were native to Yunnan. Since 1974, however, we have surveyed Malus germplasm throughout Yunnan and have found some new records of the genus, including wild $M$. sikkimensis Koehne and M. sieboldii Rehd. in the mountainous regions of northwestern Yunnan, which was the first record (1974) in the province. During 1983-84, wild $M$. formosana Kawak et Koidz. trees were found in the forests of Funing County, southeastern Yunnan. This species has several botanical forms, including one with 30 stamens and another with 45 to 50 . Therefore, 16 native Malus spp. have been confirmed in Yunnan.

Received for publication 11 Sept. 1992. Accepted for publication 21 Jan. 1993.

'Senior Researcher.

${ }^{2}$ Senior Horticulturist.
Among the 29 provinces in China, Sichuan Province has the largest number of Malus spp., Yunnan is second.

Table 1 shows the distribution, elevation, and use of Malus spp. found in Yunnan. Malus pumila and $M$. asiatica are the two cultivated species. Cultivated apple trees are distributed in 57 counties at elevations of 1850 to $2800 \mathrm{~m}$, mainly in northeastern, eastern, central, and northwestern regions of Yunnan. The optimum elevation range for apple cultivation is 2200 to $2700 \mathrm{~m}$, where trees produce highquality and brightly colored fruit. Apple trees perform poorly when grown below $1800 \mathrm{~m}$, with a higher incidence of disease and insect damage, and at insufficient chilling hours during the winter. Apple production in the province occupies a total of 20,000 ha. 'Golden Delicious', 'Delicious', 'Starking', 'Fuji', 'Qinguan', and 'Winter Banana' are the major cultivars grown in this province. Malus asiatica has a wide climatic adaptability; trees can be cultivated from subtropical areas with a 680-m elevation to the low temperate areas with a 3400-m elevation.

Malus micromalus, M. spectabilis, and $M$. prunifolia belong to a semicultivated group and are mostly grown in basins and hillsides of northwestern and northeastern Yunnan. Malus micromalus is the most popular species in the region.

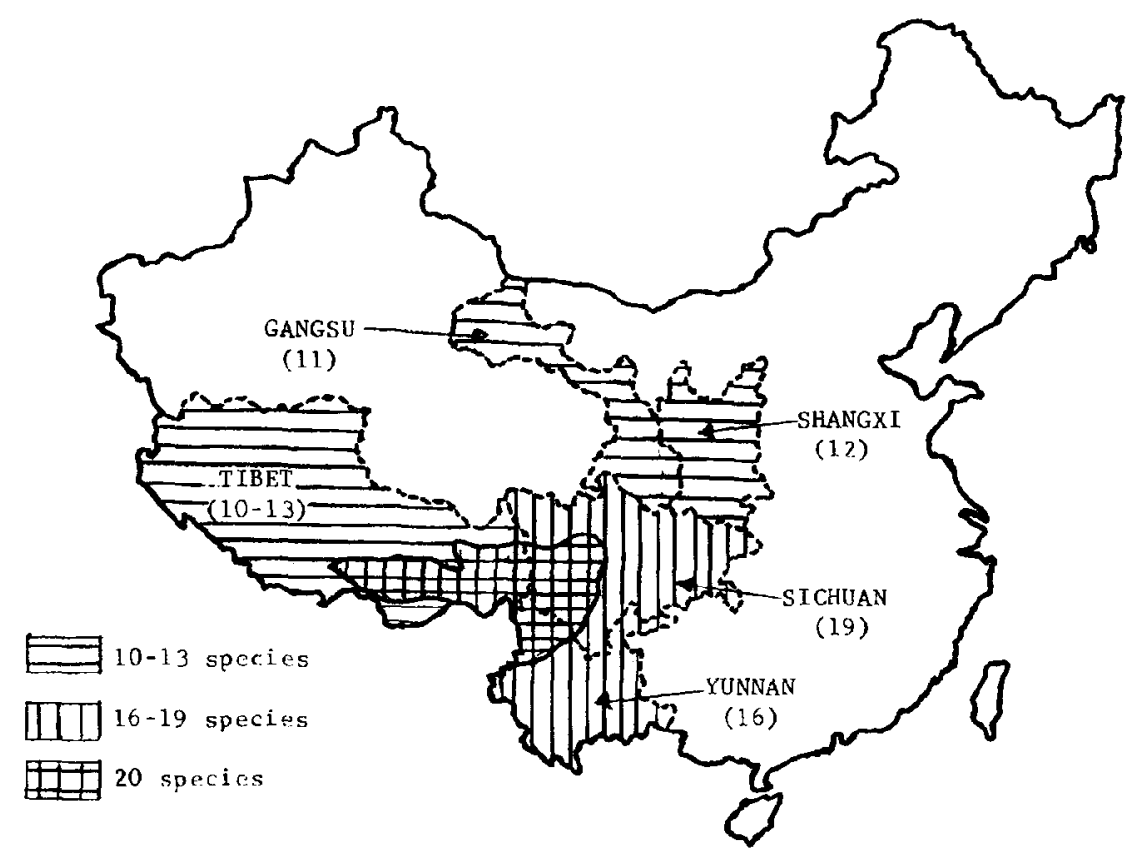

Fig. 1. Malus spp. distribution in China.
Malus rockii is widespread in northern Yunnan and distributed at 2300- to 3300-m elevations. Malus hupehensis, M. sieboldii, and $M$. yunnanensis are commonly found at 1700- to 3300-m elevations. Malus sikkimensis, M. ombrophila, M. prattii, M. formosana, and $M$. transitoria are rare, and some are becoming extinct. Malus hupehensis is widespread in the mountainous forests and riversides at 1700to 2500-m elevations. In 1974, M. sikkimensis was found in the high mountains of northwestern Yunnan at a 3600-m elevation, which is the highest elevation for Malus distribution. Wild and cultivated $M$. halliana can be found in some basin areas. Malus melliana and $M$. formosana are located only at border areas between China and Vietnam in southeastern Yunnan. In summary, there are 13 Malus spp. distributed in the Hengduan Mountains of northwestern Yunnan, 11 species in northeastern, 5 to 7 species in central, and 2 to 3 species in southeastern Yunnan (Tables 1 and 2).

\section{Uses of Malus germplasm in Yunnan}

Malus pumila Mill. The local apple (Chinese apple or soft apple) has been cultivated for a long time in many areas of Yunnan, including Kunming, Lijiang, Zhaotong, and Dali. But there are few local apple orchards because of the apple's poor quality (soft flesh 


\begin{tabular}{|c|c|c|c|}
\hline Species & $\begin{array}{l}\text { Native } \\
\text { geographical } \\
\text { region }\end{array}$ & $\begin{array}{c}\text { Elevation } \\
\text { (m) }\end{array}$ & Uses \\
\hline \multicolumn{4}{|l|}{ Cultivated } \\
\hline M. pumila & Most of Yunnan & $1850-2800$ & Fresh fruit \\
\hline M. asiatica & Most of Yunnan & $680-3400$ & Fresh fruit \\
\hline \multicolumn{4}{|l|}{ Semicultivated } \\
\hline M. micromalus & North & & Fresh fruit, rootstock, processing \\
\hline M. spectabilis & Northwest and northeast & & As above \\
\hline M. prunifolia & Northwest and northeast & & As above \\
\hline \multicolumn{4}{|l|}{ Wild } \\
\hline M. rockii & Northwest and northeast & $2300-3300$ & Rootstock, ornamental \\
\hline M. hupehensis & Central & $1700-2500$ & As above \\
\hline M. halliana & North & $1900-2300$ & Ornamental \\
\hline M. transitoria & Central & $1900-2100$ & As above \\
\hline M. sieboldii & Northwest and northeast & $2300-3300$ & Rootstock, ornamental \\
\hline M. sikkimensis & Northwest & $\approx 3600$ & As above \\
\hline M. yunnanensis & Northwest and northeast & $2300-3300$ & As above \\
\hline M. ombrophila & Northwest & & \\
\hline$M \cdot$ prattii & Northwest and northeast & $2300-3300$ & \\
\hline M. melliana & Southeast & & Fresh fruit \\
\hline M. formosana & Southeast & $950-1100$ & Fresh fruit \\
\hline
\end{tabular}

Table 2. Malus spp. distribution in western Sichuan, northwestern Yunnan, and eastern Tibet.

\begin{tabular}{|c|c|c|c|}
\hline Species & Sichuan & Yunnan & Tibet \\
\hline M.baccata & $\mathrm{Y}$ & & $\mathbf{P}$ \\
\hline M. mandshurica & $Y$ & & $\mathrm{Y}$ \\
\hline$M$. rockii & $\mathbf{Y}$ & $Y$ & $\mathbf{Y}$ \\
\hline M. hupehensis & $\mathbf{Y}$ & & $\mathrm{P}$ \\
\hline M. sikkimensis & $\mathbf{Y}$ & $Y$ & $\mathbf{Y}$ \\
\hline M. xiaojinensis & $Y$ & & \\
\hline M. halliana & $\mathrm{Y}$ & $\mathbf{Y}$ & $\mathbf{Y}$ \\
\hline M. pumila & $\mathrm{Y}$ & $\mathbf{Y}$ & $\mathrm{Y}$ \\
\hline M. asiatica & $\mathbf{Y}$ & $\mathbf{Y}$ & $\mathbf{Y}$ \\
\hline M.prunifolia & $\mathbf{Y}$ & $\mathbf{Y}$ & $\mathrm{Y}$ \\
\hline M. spectabilis & & $\mathrm{Y}$ & \\
\hline M. micromalus & Y & $\mathrm{Y}$ & $\mathrm{P}$ \\
\hline M. sieboldii & $\mathbf{Y}$ & $\mathrm{Y}$ & \\
\hline M. kansuensis & $\mathrm{Y}$ & & \\
\hline M. komarovii & $\mathbf{Y}$ & & \\
\hline M. transtoria & $\mathbf{Y}$ & $\mathbf{Y}$ & $\mathbf{Y}$ \\
\hline M. yunnanensis & $\mathbf{Y}$ & $\mathbf{Y}$ & $\mathrm{Y}$ \\
\hline$M$. prattii & $\mathrm{Y}$ & $\mathrm{Y}$ & \\
\hline M. honanensis & $\mathbf{Y}$ & & \\
\hline M. ombrophila & $\mathbf{Y}$ & $\mathrm{Y}$ & $\mathbf{Y}$ \\
\hline Total number & & & \\
\hline of species & 19 & 13 & $10-13$ \\
\hline
\end{tabular}

זY =yes, $\mathrm{P}=$ probably yes; the other three Malus spp in other regions of Yunnan have not been listed here.

and little juice). The common apple (Malus $\times$ domestica Borkh.), called "Western apple" in China, was introduced into Yunnan in 1931 and replaced local apple cultivation.

Malus asiatica Nakai. Malus asiatica (Huahong in Chinese) is widespread in central and northern Yunnan. It is very popular because of its early ripening (June to July), bright red pigmentation, and aroma. Fruit weighs $\approx 20$ to $50 \mathrm{~g}$ and is eaten fresh or processed as preserves.

Malus micromalus Makina. Malus micromalus is eaten fresh, canned, or processed as preserves. As a dried product, it is used as a Chinese medicine to suppress coughing. This species is one of the major apple rootstock in Yunnan, and seedlings grow vigorously. Graft compatibility of $M$. micromalus rootstock with local and common apples is very high, and grafted trees are productive. The seedlings, however, are not

Fig. 2. Malus spp. distribution in Yurnan Province. preserves. When dried, it is a Chinese medicine for controlling coughing. It also serves as an apple rootstock with good graft compatibility. In addition to seed propagation, clonal propagation can be conducted using cuttings or suckers. This species has ornamental value, producing red blooms and red or yellow fruit.

Malus spectabilis (Ait.) Borkh. The fruit of this species can be eaten fresh. Seedlings grow well and have good graft compatibility with local and common apples. It is not widely used as a rootstock because seed collection is difficult.

Malus sikkimensis Koehne. Local people use this fruit as a dessert apple. Seedlings grow vigorously and uniformly and show resistance to $P$. leucotricha. When used as a rootstock, graft compatibility varies widely among scion cultivars, a characteristic that should be investigated further. It is also a good ornamental tree, which produces pink blooms and bright red fruit.

Malus melliana (Hand-Mazz.) Rehd. The uniform and are susceptible to Podosphaera leucotricha (Ell. et Ev.) Salm. and Armillariella tabescens (Scop. ex Fr.) Sing. This material can be useful for selecting superior rootstock. In addition, it is a good ornamental tree, which produces a showy bloom in the spring and red leaves in the fall.

Malus prunifolia Borkh. Malus prunifolia can be eaten fresh, canned, or processed as fruit of this species ripens in July and can be eaten fresh. It has not been tested as a rootstock for local or common apple cultivars.

Malus formosana Kawak. et Koidz. Malus formosana fruit is larger and the flesh is firmer than that of most other Malus spp. It can be eaten fresh or processed as preserves, but has not been evaluated as a rootstock for apple.

Malus rockii Rehd. Seedlings of this spe-

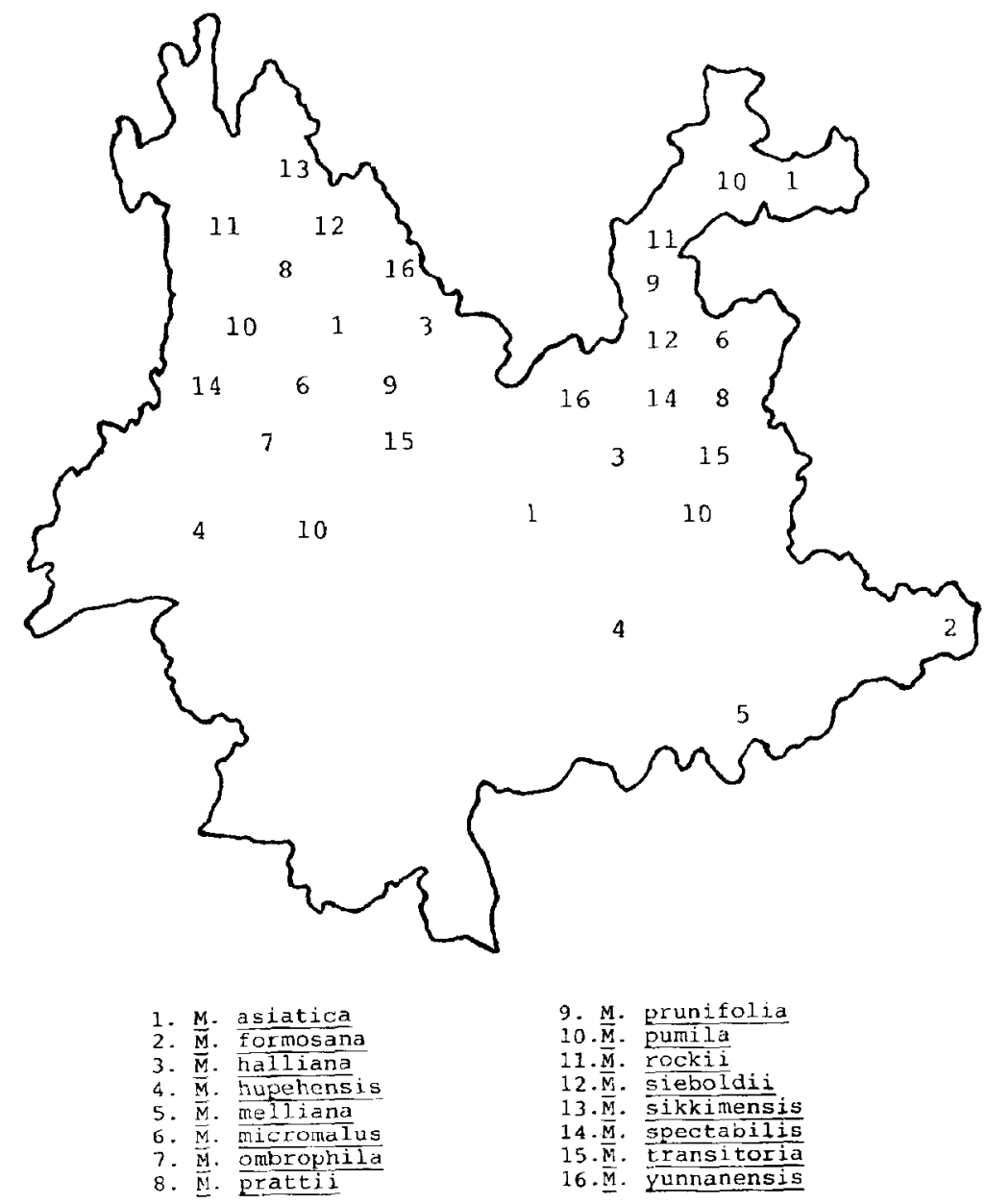


cies grow vigorously and show resistance to $P$. leucotricha. Graft compatibility with scion cultivars is good, and grafted trees are productive, with resistance to drought and waterlogging. Malus rockii is one of the major rootstocks for apple in Yunnan.

Malus hupehensis Rehd. Seedlings of $M$. hupehensis grow well and uniformly and show resistance to drought and $P$. leucotricha. Graft compatibility with apple cultivars is variable. It is a good ornamental tree and tends to be apomictic.

Malus sieboldii Rehd. Seedlings have low vigor and show resistance to drought and powdery mildew. A high level of graft incompatibility with common apple has been observed, and the budding union is easy to crack. Grafted trees exhibit dwarfing characteristics.

Malus yunnanensis Schneid. Seedlings are not uniform and have a high level of graft incompatibility. Grafted trees are dwarfed, fruit early, and develop an enlarged graft union. This is a good ornamental tree, which produces yellow fruit and large red leaves in the fall.

Malus halliana Koehne. A major ornamental tree in Yunnan, Malus halliana is grown in central and northern regions of the province. It blooms in March with attractive heavy red and pink flowers produced either as a single flower or as multiple flowers per bud. Layering is commonly used for propagating cuttings.

Malus transitoria Schneid. This beautiful tree produces attractive flowers, sawtooth leaves, and large quantities of small fruit.

Little research has been done with $M$. ombrophila Hand-Mazz. and M. prattii Schneid., although they are closely related

\section{Possible role of northwestern Yunnan in the origin of Malus}

According to $\mathrm{Yu}(1978,1979)$ and $\mathrm{Li}$ (1989), there are 37 to 60 species of Malus in the world, 24 of which are distributed in China. Most of the species can be found in the western parts of Sichuan and Yunnan provinces, a region called the Chuan-Dian Palaeoland. This area has the highest density of Malus spp. and is a major genetic center of Malus in the world. Our investigation shows that the southwestern region of China, including northwestern Yunnan, western Sichuan, and eastern Tibet, might be the largest center of Malus diversity in the world (Figs. 1 and 2). The following evidence supports the above conclusions.

1) Twenty Malus spp. are found in southwestern China, 19 of which are in western Sichuan, 13 in northwestern Yunnan, and 10 to 13 in eastern Tibet (Table 2). The species in this area constitutes $\approx 83 \%$ of the total number of Malus spp. found in China and 50\% to 55\% of the total 36 to 40 species that exist in the world. This area, therefore, provides the most concentrated and largest gene pool of this genus. Occupying one-sixth of the total area of the Yunnan Province $\left(60,000 \mathrm{~km}^{2}\right)$, the Hwengdwang Mountains of northwestern Yunnan are the home of 13 Malus spp. (eight wild species and five semicultivated and cultivated species). Different forms of each species have been identified. For example, there are 25 forms of Malus rockii and eight forms each of $M$. sikkimensis and M. hupehensis. Intraspecific diversity among those different forms requires further investigation.

2) Nineteen genera of the Rosaceae family exist in China. All, including Amygdalus, Armeniaca, Cerasus, Chaenomeles, Cotoneaster, Crataegus, Cydonia, Docynia, Eriobotrya, Fragaria, Malus, Padus, Photinia, Prinsepia, Prunus, Pyrus, Rosa, Rubus, and Sorbus, are native to northwestern Yunnan. Other wild fruits and nuts, including 24 families, 43 genera, 138 species and varieties, and 81 types, are widespread in this area. Most of the above germplasm also exists in western Sichuan and eastern Tibet.

3) Northwestern Yunnan has a diverse topography and climate, ranging from subtropical river valleys to frigid high mountains. The Chuan-Dian Polaeoland was not affected by a great glacier. In addition, human population densities are sparse, and humans have had relatively little influence on the plant population. Many living plant fossils have been found in this area. For example, records of Malus rockii trees with trunk circumference of 2.7 to
$3.1 \mathrm{~m}$ were found at a $3400-\mathrm{m}$ elevation. In addition, fossil records show M. sikkimensis trees with trunk circumferences of 2.6 to 3.0 $\mathrm{m}$, and $M$. yunnanensis with trunk circumferences of 5.0 to $5.4 \mathrm{~m}$.

\section{Literature Cited}

Cheng, M., N. Jiang, and W. Zeng. 1983. A new species of Malus Miller (in English and Chinese). J. Southwestern Agr. College. 1983(4):2022

Hu, X.L. 1988. Fruit germplasm resources in Yunnan, China. Part I, Fruit trees. Intl. Symp. Horticultural Germplasm, 5-9 Sept. 1988, Beijing. p. 208-214.

Li, Y. 1989. An investigation of the genetic center of Malus pumila and Malus in the world (in Chinese, English abstract). Acta Hort. Sinica 16:101108

Wu, Z. 1984. List of seed plants in Yunnan (in Chinese). Yunnan People's Publishing House, Kunming, China. p. 482-484.

Yu, D. 1978. China's flora (in Chinese). vol. 36. Scientific Publishing House, Beijing. p. 102405.

Yu, D. 1979. China's fruit taxonomy (in Chinese). Agricultural Publishing House, Beijing. p. 25171, 209-226, 309-316. 